OPEN ACCESS

Edited by:

Junjun Chen,

The Education University of Hong Kong, Hong Kong

Reviewed by:

Xin Zheng,

Southwest University, China Adam M. Croom, The University of California, Merced, United States

*Correspondence:

Petruta P. Rusu

petruta.rusu@usm.ro

tThese authors have contributed equally to this work and share first authorship

Specialty section:

This article was submitted to Educational Psychology, a section of the journal Frontiers in Psychology

Received: 28 February 2020 Accepted: 15 June 2020

Published: 22 July 2020

Citation:

Rusu PP and Colomeischi AA (2020) Positivity Ratio and Well-Being Among Teachers. The Mediating Role of Work Engagement. Front. Psychol. 11:1608. doi: 10.3389/fpsyg.2020.01608

\section{Positivity Ratio and Well-Being Among Teachers. The Mediating Role of Work Engagement}

\author{
Petruta P. Rusu*t and Aurora A. Colomeischit \\ Department of Educational Sciences, University "Stefan cel Mare" of Suceava, Suceava, Romania
}

Previous studies indicated that the balance of positive to negative affect (i.e., positivity ratio) is associated with subjective well-being and flourishing in the general population. Moreover, a positivity ratio of 2.9 is considered a critical value discriminating between flourishing and non-flourishing individuals. To date, however, there is limited research on the positivity ratio on samples of teachers. The present study aimed to investigate whether the positivity ratio affects work engagement and well-being among teachers. Based on the broaden-and-build theory (Fredrickson, 2001) and work engagement model (Bakker and Demerouti, 2007), we predicted that positivity ratio (the ratio between positive and negative emotions) experienced by teachers would increase their work engagement, which in turn would positively affect their well-being. A sample of 1,335 teachers (762 women and 573 men) from Romania participated in the study. Results revealed that work engagement mediated the relationship between positivity ratio and well-being. Specifically, teachers with a higher ratio of positive to negative emotions reported more engagement (dedication, absorption, and vigor) and in consequence higher levels of subjective well-being (autonomy, environmental mastery, personal growth, self-acceptance, positive relations with others and purpose in life). Also, when investigating the positivity ratio according to participants' well-being, we found a mean of positivity ratio of 2.84 for the group of teachers with high levels of well-being, validating the proposed critical positivity ratio of 2.9. These findings support the importance of addressing positive emotions and positivity ratio in prevention and intervention programs with teachers.

Keywords: positive emotions, negative emotions, positivity ratio, work engagement, teachers' well-being

\section{INTRODUCTION}

Teachers are emotional workers (Yin, 2015). Teachers' emotions have been found to influence their performance, self-efficacy, job satisfaction, burnout, and instructional effectiveness (classroom management, teacher support for students, student-centered approaches to teaching, and cognitive and motivational stimulation provided to students) (Frenzel, 2014; Taxer and Frenzel, 2015; Lavy and Eshet, 2018; Chen, 2019a,b). Thus far, most of the existing studies focused on teachers' negative emotions such as depression or anxiety and their associations with job burnout and occupational stress (Desouky and Allam, 2017; Capone et al., 2019). Although empirical research on teachers' emotions increased in the last decade, there is still limited research considering teachers' positive emotions and how positive emotions affect individual and organizational outcomes. This is surprising since teachers experience at the same time negative 
emotions (such as anger, anxiety, shame, and boredom) and positive emotions (such as enjoyment, pride, love and caring) (Frenzel, 2014; Buriæ et al., 2018, 2019; Lee and van Vlack, 2018). According to the broaden-and-build theory (Fredrickson, 2001), experiencing positive emotions prompt individuals to be more engaged in activities and increase their psychological well-being. Similarly, the happy-productiveworker theory conceptualizes positive emotions as antecedents of work engagement and satisfaction (see for review GarcíaBuades et al., 2019). Organizational studies indicated that positive emotions have been positively associated with self-efficacy, hope, optimism, job satisfaction, and flow at work (Siu et al., 2015; Zito et al., 2019). Another line of research considered that an important predictor of well-being and flourishing is the balance between positive and negative affect (i.e., positivity ratio) (Fredrickson and Losada, 2005). Positivity ratio was positively related to life satisfaction, self-control, self-esteem, and optimism (Shrira et al., 2016; Orkibi and Ronen, 2017). However, only a few studies considered positivity ratio in teachers, and to our knowledge, there is no empirical study in educational context investigating the associations of positivity ratio with work engagement and well-being. Moreover, most of the existing studies involving teachers' emotions have been conducted on samples of teachers from the United States and Western Europe, and the generalization of the findings to teachers from Eastern Europe may be limited. The present study aims to address these gaps by investigating whether teachers' positivity ratio is associated with their well-being through the mediating role of work engagement. Based on the aforementioned theories and research, we suggest not only that positive emotions are important but also that the affective balance between positive and negative emotions would be associated with teachers' engagement and well-being. Given the limited number of studies on teachers from Eastern Europe, the current study focused on a sample of teachers from Romania.

\section{Benefits of Teachers' Positive Emotions}

Positive emotions transform both individuals and organizations, leading to growth and development (Fredrickson, 2000). The broaden-and-build theory (Fredrickson, 2001) assumes that positive emotions broaden the array of thoughts and actions (e.g., to explore, to be creative, and to savor life experiences), which in consequence build personal resources (e.g., psychological wellbeing and resilience). Studies based on the broaden-and-build theory indicated that positive emotions at work contribute to positive outcomes, including enduring personal resources (such as work engagement, positive beliefs, creativity, and effective coping strategies), social outcomes (such as good relationships at work and cooperation), and job performance (see, for review, Diener et al., 2020). In general, positive emotions have been positively associated with work well-being, self-efficacy, hope, optimism, adaptive coping, resilience, job satisfaction, emotional intelligence, creativity, and flow at work (Parke et al., 2015; Siu et al., 2015; Gloria and Steinhardt, 2016; Zito et al., 2019). In contrast, existing studies reported negative relationships between positive emotions and stress symptoms, turnover intentions, maladaptive coping, depression, and anxiety (Siu et al., 2015;
Gloria and Steinhardt, 2016). Positive emotions also trigger upward spirals, as their positive consequences predict future increases in positive emotions and lead further to well-being (Fredrickson and Joiner, 2002, 2018).

In the context of teaching profession, studies indicated that teachers' positive emotions have been positively related to their self-efficacy, work engagement, performance, job satisfaction, life satisfaction, enthusiasm, and positive student behaviors, while negative emotions have been associated with less work engagement, lower levels of self-efficacy, and lower performance (Brígido et al., 2013; Buriæ and Macuka, 2018; Chen, 2019b; Buriæ and Moè, 2020). Specifically, positive emotions of joy and love in teaching have been positively associated with performance, teachers' sense of self-efficacy, student-centered approaches to teaching, and student focus (Chen, 2019a,b). Also, a recent longitudinal study revealed that positive affective experiences have an important role in shaping teachers' selfefficacy and job satisfaction, which in turn were positively related to teachers' enthusiasm (Buriæ and Moè, 2020). The spiral effects of emotions have been supported in a daily diary conducted on a sample of teachers, which showed that teachers' daily positive emotions trigger an upward spiral leading to job satisfaction, while negative emotions prompt a downward spiral leading to burnout (Lavy and Eshet, 2018). Existing research considering other emotional aspects of teachers' lives showed that teachers' adaptive emotion regulation strategies (such as reappraisal) and emotional intelligence were positively associated with long-term well-being, job satisfaction, and expression of naturally felt emotions, while emotional job demands of teaching affected teachers' well-being by determining emotional exhaustion (Yin, 2015; Yin et al., 2016, 2018, 2019).

\section{Positivity Ratio}

Positivity ratio, the ratio of positive to negative affect, was conceptualized as a key predictor of well-being and flourishing (Fredrickson and Losada, 2005). Moreover, research suggests that the critical value of the positivity ratio distinguishing between flourishing and non-flourishing individuals is 2.9:1 (Fredrickson and Losada, 2005).

This specific value of positivity ratio and the formula for calculating it have been criticized later on (Brown et al., 2013). Moreover, a recent study indicated a curvilinear relationship between positivity ratio and exhaustion, suggesting that after exceeding a specific value (i.e., 2.0), the positivity ratio may lead to negative outcomes, such as work exhaustion (Basińska and Gruszczyńska, 2017). Despite the criticisms and disapprovals regarding the existence of a specific value for the positivity ratio for distinguishing between "flourishing" and "languishing" individuals, Brown et al. (2013) did not criticize the construct on its own and they agreed that positivity ratio might be associated with positive outcomes. Thus far, research found positive associations of positivity ratio with emotional intelligence, life satisfaction, optimism, self-esteem, and self-control (Shrira et al., 2016; Orkibi and Ronen, 2017; Moroń, 2018) and negative associations with job burnout (Basińska and Gruszczyńska, 2017). 
A few empirical studies investigated the ratio between positive and negative emotions in an educational context. Specifically, teachers' hedonic balance (computed as the difference between positive and negative emotions) was positively associated with teachers' self-efficacy, job satisfaction, and student-related positive emotions (Buonomo et al., 2019, 2020). Research supporting the broaden-and-build theory among teachers also revealed that positive emotions can reduce the negative effects of negative emotions (i.e., undoing effect) (Gloria et al., 2013; Buonomo et al., 2019). At the same time, studies investigating both teachers' positive and negative emotions revealed that in general low levels of positive emotions reported by teachers (such as enjoyment and pride) and high levels of negative emotions (such as anger and anxiety) correspond to higher levels of emotional exhaustion, teacher burnout, and emotional labor (Keller et al., 2014; Khajavy et al., 2017; Wang et al., 2019). Therefore, we suggest that the balance of positive to negative emotions should be considered in studies investigating teachers' well-being. The present study will investigate the relationships between positivity ratio, work engagement, and psychological well-being among Romanian teachers.

\section{Emotions, Work Engagement, and Well-Being}

Based on the job demands-resources model (JD-R Model, Bakker and Demerouti, 2007), higher levels of employee well-being are determined by job resources through work engagement, while lower levels of well-being are predicted by job demands through burnout. Work engagement was defined as a positive attitude toward work characterized by vigor (high levels of energy and perseverance), dedication (work involvement, enthusiasm, and inspiration), and absorption (work immersion and concentration) (Schaufeli et al., 2002).

Studies testing the JD-R model showed that personal resources (self-esteem, optimism, self-efficacy, and active coping) have been positively related to work engagement and psychological wellbeing and negatively associated with exhaustion (Xanthopoulou et al., 2007; Lee, 2019). Positive emotions play also an important role in work engagement. Fredrickson (2000) suggested that the items used by Gallup for measuring employees' engagement target indirectly positive emotions and that the positive influence of engagement on organizational outcomes derives from positive emotions. A review including cross-sectional, longitudinal, and experimental studies indicated that positive emotions affect work life as they are related to better work quality, higher job performance, cooperation, reduced conflict with colleagues, prosocial organizational behavior, and better income (Lyubomirsky et al., 2005). In general, work engagement was positively related to positive emotions and negatively associated to negative emotions and emotional exhaustion (Sonnentag et al., 2008; Malinowski and Lim, 2015; Dicke et al., 2018; Bakker et al., 2019; Moreira-Fontán et al., 2019).

Studies conducted on teachers support the beneficial effects of positive emotions on work performance, teaching self-efficacy, mental health, and job satisfaction (Taxer and Frenzel, 2015; Lavy and Eshet, 2018). Buriæ and Macuka (2018) found that teachers' positive emotions of joy, love, and pride have been related to higher levels of work engagement 6 months later, while negative emotions of anger, fatigue, and hopelessness were negatively related to engagement. In contrast, another study showed that emotional exhaustion was negatively related to teachers' work engagement and job satisfaction (Han et al., 2019).

Regarding the relationship between work engagement and well-being, existing research found positive associations. Higher levels of cognitive, emotional, and physical engagement have been positively related to well-being and personal accomplishment (Shuck and Reio, 2014). Vigor, dedication, and absorption have been positively associated with job satisfaction (Yan et al., 2019). Recent empirical studies also found positive relationships between work engagement and job satisfaction among teachers (Perera et al., 2018; Han et al., 2019). Most of the existing studies testing the JD-R model conceptualized wellbeing through job satisfaction, work burnout, and emotional exhaustion (Mencl et al., 2016; Khajavy et al., 2017; Ferreira et al., 2019; Lesener et al., 2019), and few studies investigated psychological well-being. The present study will investigate whether teachers' emotions are linked to work engagement and psychological well-being.

\section{Hypotheses}

According to the broaden-and-build theory (Fredrickson, 2001) and JD-R model (Bakker and Demerouti, 2007) and based on existing studies showing significant associations of positive and negative emotions with work engagement (Sonnentag et al., 2008; Malinowski and Lim, 2015; Buriæ and Macuka, 2018) and psychological well-being (Lavy and Eshet, 2018), we first assumed that positive emotions and the positivity ratio will be positively associated with teachers' work engagement and psychological well-being. Second, considering the positive associations of work engagement with well-being and flourishing (Robledo et al., 2019; Tesi et al., 2019), we predicted that teachers' work engagement will be positively related to psychological well-being. Third, as our main hypothesis, we predicted that teachers' work engagement will mediate the association of emotions and positivity ratio with psychological well-being. This hypothesis is derived from the JD$\mathrm{R}$ model (Bakker and Demerouti, 2007) and studies supporting this model (see for review Lesener et al., 2019), assuming that personal resources are related to positive individual and organizational outcomes. In order to test these hypotheses, we tested two separate models, one considering positive and negative emotions separately as independent variables and the second one considering the positivity ratio as an independent variable.

\section{METHOD}

\section{Sample}

The sample consisted of 1,335 teachers (762 women and 573 men). Participants had a mean age of $39.19(S D=10.55$, range $=18-68)$. On average, teachers had a work experience of 15.04 years $(S D=11.07$, range $=0-48$ years $)$. Participating teachers worked in all school levels: preschool (16.4\%), primary school (39.6\%), middle school (30\%), and high school (14.1\%). 
Approximately half of the teachers worked in an urban area (53.3\%) and half of them in a rural area (46.7\%). Regarding their marital status, $74.4 \%$ were married, $21.4 \%$ were not married, $2.7 \%$ were divorced, and $1.4 \%$ were widowed.

\section{Procedure}

Participating teachers in the present study were recruited by students attending an educational science program from a public Romanian university. Students were instructed to distribute the questionnaires to teachers. The Institutional Review Board of the Romanian University approved the study. All participants signed informed consent. Teachers were not reimbursed for participation in this study. Students received course credits for data collection.

\section{Measures}

Teachers completed demographic information regarding age, gender, education, work experience, marital status, and school level where they teach.

\section{Emotions}

The Positive Affect and Negative Affect Scale (PANAS, Watson et al., 1988) was used to assess positive and negative emotions. PANAS is a 20 -item questionnaire that measures positive emotions (e.g., enthusiastic, proud, and inspired) and negative emotions (e.g., distressed, upset, and guilty) by asking participants to rate the frequency with which they experience various emotions on a 5-point Likert scale ranging from 1 (very slightly or not at all) to 5 (extremely). Internal consistency in this study was $\alpha=0.78$ for positive affect and $\alpha=0.80$ for negative affect.

\section{Work Engagement}

The Utrecht Work Engagement Scale (UWES, Seppälä et al., 2009) was used to measure teachers' engagement at work. UWES consists of 17 items grouped into three factors: vigor (e.g., At my work, I always persevere, even when things do not go well), dedication (e.g., I find the work I do full of meaning and purpose), and absorption (e.g., When I am working, I forget everything else around $m e$ ). Participants reported their level of agreement with each item on a 7-point Likert scale ranging from 0 (never) to 6 (always/every day). In our study, Cronbach's alpha was $\alpha=0.78$ for each subscale.

\section{Well-Being}

The Psychological Well-being Scale (Ryff, 1989) was used to measure teachers' well-being. The scale consists of 84 items which measure the six underlying dimensions of well-being: autonomy (e.g., My decisions are not usually influenced by what everyone else is doing), personal growth (e.g., I have the sense that I have developed a lot as a person over time), self-acceptance (e.g., In many ways, I feel disappointed about my achievements in life), positive relations with others (e.g., People would describe me as a giving person, willing to share my time with others), environmental mastery (e.g., I do not fit very well with the people and the community around me), and purpose in life (e.g., I enjoy making plans for the future and working to make them a reality). Items are rated on a 6-point Likert scale from 1 (completely disagree) to 6 (completely agree). In the present study, Cronbach's alpha was $\alpha=0.77$ for autonomy, $\alpha=0.76$ for personal growth, and $\alpha=0.75$ for self-acceptance, positive relations, environmental mastery, and purpose in life.

\section{Analytic Strategy}

We used SPSS 22 for descriptive statistics, correlations, and $t$-tests. In order to estimate the structural model, we used Mplus 7.11 (Muthén and Muthén, 1998). The following common fit indices were considered: comparative fit index (CFI), TuckerLewis index (TLI), standardized root mean square residual (SRMR), and root mean square residual of approximation (RMSEA) (Schermelleh-Engel et al., 2003). We used full information maximum likelihood estimator and bootstrap option in Mplus to compute model parameters and standard errors. In testing the mediation models, positive and negative emotions and positivity ratio were considered as manifest variables, while engagement and well-being were considered as latent variables (Figures 1, 2).

\section{RESULTS}

\section{Descriptive Statistics}

Means, standard deviations, and the results of the $t$-test for independent samples across gender for each of the study variables are presented in Table 1. Overall, teachers reported relatively moderate levels of positive emotions and low levels of negative emotions. In terms of engagement, participants reported moderate levels of dedication, moderate levels of absorption, and high levels of vigor. In regard to well-being, participants indicated moderate levels of autonomy, personal growth, self-acceptance, positive relations, environmental mastery, and purpose in life. Results also indicated that women reported higher levels of dedication, absorption, autonomy, personal growth, purpose in life, and higher total scores for engagement and well-being than men. In addition, men reported higher levels of negative affect than did women.

The intercorrelations between the study variables are presented in Table 2. Results show significant positive correlations of positivity ratio with engagement subscales (dedication, absorption, and vigor) and well-being subscales (autonomy, personal growth, self-acceptance, positive relations, environmental mastery, and purpose in life). Moreover, the three engagement scales were significantly positively correlated with well-being subscales.

\section{Path Analysis Results}

The first model included positive and negative emotions as independent variables, well-being as a dependent variable, and work engagement as a mediator (Figure 1). Model 1 showed a satisfactory fit: CFI $=0.98, \mathrm{TLI}=0.97, \mathrm{RMSEA}=0.05,90 \% \mathrm{CI}$ $[0.04,0.06]$, SRMR $=0.02$. The second model included positivity ratio as an independent variable (Figure 2). This model had also acceptable fit indices: $\mathrm{CFI}=0.98, \mathrm{TLI}=0.97$, RMSEA $=0.06,90 \%$ CI $[0.05,0.06]$, SRMR $=0.02$. 


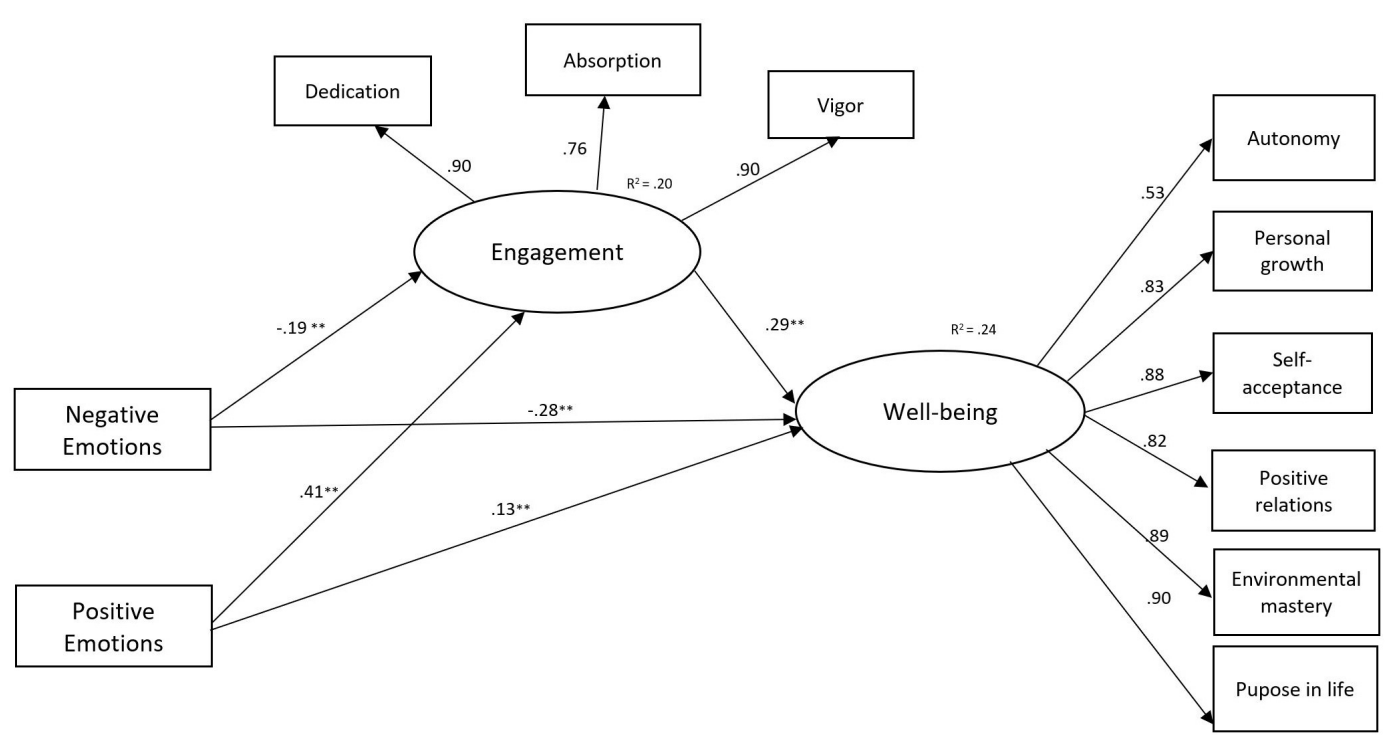

FIGURE 1 | Standardized coefficients for the first mediation model, including positive emotions, negative emotions, engagement and well-being. Note: $n=1335$, ${ }^{\star \star} p$ $<0.01$ (two-tailed).

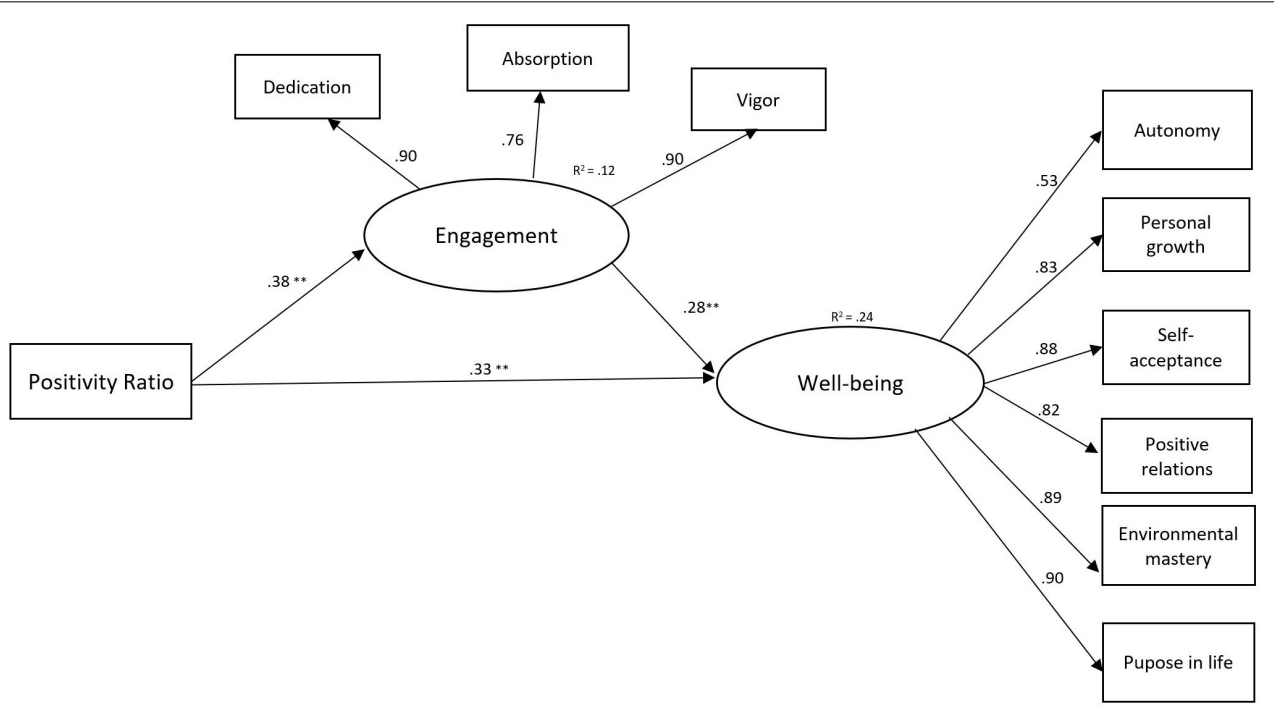

FIGURE 2 | Standardized coefficients for the second mediation model, including positivity ratio, engagement and well-being. Note: $n=1335,{ }^{* *} p<0.01$ (two-tailed).

\section{Direct Effects}

In Model 1 (Figure 1), the results indicated that positive emotions had a positive effect on engagement $(\beta=0.41, p<0.001)$ and well-being $(\beta=0.13, p<0.001)$ while negative emotions had a negative effect on both engagement $(\beta=-0.19, p<0.001)$ and well-being $(\beta=-0.28, p<0.001)$. Moreover, engagement had a positive direct effect on well-being $(\beta=0.29, p<0.001)$.

In Model 2 (Figure 2), we considered the ratio of positive to negative emotions as a predictor of engagement and well-being. The findings revealed that the positivity ratio had a significant positive direct effect on engagement $(\beta=0.38, p<0.001)$ and well-being $(\beta=0.33, p<0.001)$, while engagement had a significant positive direct effect on well-being $(\beta=0.28$, $p<0.001)$.

\section{Indirect Mediation Effects}

In Model 1, both positive emotions and negative emotions had an indirect effect on well-being through the mediating role of engagement $(\beta=0.12, p<0.01$ for positive emotions and $\beta=-0.05, p<0.01$ for negative emotions).

In Model 2, the results showed that the positivity ratio had a significant indirect effect on well-being through the mediating role of engagement $(\beta=0.11, p<0.01)$. 


\section{DISCUSSION}

Being a teacher is an important role that involves generativity, as teachers influence not only students but also the whole community through the dissemination of knowledge, values, and beliefs (Branand and Nakamura, 2016). Thus, it is important to

TABLE 1 | Descriptive statistics and independent sample $t$-test for path model variables.

\begin{tabular}{|c|c|c|c|c|c|}
\hline Variable & Mean & SD & $\begin{array}{c}\text { Mean } \\
\text { difference }\end{array}$ & $t$ & Cohen's d \\
\hline \multicolumn{6}{|c|}{ Positive affect } \\
\hline Women & 35.94 & 6.36 & 0.27 & 0.77 & 0.04 \\
\hline Men & 36.21 & 6.42 & & & \\
\hline \multicolumn{6}{|c|}{ Negative affect } \\
\hline Women & 16.07 & 6.36 & $0.75^{\star}$ & 2.12 & 0.11 \\
\hline Men & 16.83 & 6.47 & & & \\
\hline \multicolumn{6}{|c|}{ Positivity ratio } \\
\hline Women & 2.53 & 0.91 & -0.08 & -1.63 & 0.09 \\
\hline Men & 2.44 & 0.93 & & & \\
\hline \multicolumn{6}{|c|}{ Dedication } \\
\hline Women & 25.43 & 3.99 & $-0.80^{\star \star}$ & -3.68 & 0.20 \\
\hline Men & 24.62 & 3.87 & & & \\
\hline \multicolumn{6}{|c|}{ Absorption } \\
\hline Women & 27.80 & 5.15 & $-1.33^{\star \star}$ & -4.58 & 0.25 \\
\hline Men & 26.47 & 5.37 & & & \\
\hline \multicolumn{6}{|l|}{ Vigor } \\
\hline Women & 28.73 & 4.67 & -0.35 & -1.41 & 0.07 \\
\hline Men & 28.37 & 4.46 & & & \\
\hline \multicolumn{6}{|c|}{ Engagement } \\
\hline Women & 81.96 & 12.67 & $-2.49^{\star \star}$ & -3.61 & 0.19 \\
\hline Men & 79.47 & 12.23 & & & \\
\hline \multicolumn{6}{|c|}{ Autonomy } \\
\hline Women & 55.99 & 7.42 & $-1.12^{\star \star}$ & -2.70 & 0.14 \\
\hline Men & 54.87 & 7.63 & & & \\
\hline \multicolumn{6}{|c|}{ Personal growth } \\
\hline Women & 63.70 & 9.28 & $-1.77^{\star \star}$ & -3.49 & 0.19 \\
\hline Men & 61.93 & 9.08 & & & \\
\hline \multicolumn{6}{|c|}{ Self-acceptance } \\
\hline Women & 62.87 & 10.11 & -1.07 & -1.94 & 0.10 \\
\hline Men & 61.80 & 9.81 & & & \\
\hline \multicolumn{6}{|c|}{ Positive relations } \\
\hline Women & 63.86 & 10.55 & -0.95 & -1.62 & 0.09 \\
\hline Men & 62.90 & 10.77 & & & \\
\hline \multicolumn{6}{|c|}{ Environmental mastery } \\
\hline Women & 62.98 & 9.66 & -0.32 & -0.59 & 0.03 \\
\hline Men & 62.66 & 9.90 & & & \\
\hline \multicolumn{6}{|c|}{ Purpose in life } \\
\hline Women & 64.33 & 9.78 & $-1.55^{\star \star}$ & -2.86 & 0.15 \\
\hline Men & 62.77 & 9.88 & & & \\
\hline \multicolumn{6}{|c|}{ Well-being } \\
\hline Women & 373.75 & 47.96 & $-6.81^{\star}$ & -2.53 & 0.13 \\
\hline Men & 366.94 & 49.43 & & & \\
\hline
\end{tabular}

$n=762$ women and 573 men, $d f=1333 .{ }^{*} p<0.05$ (one-tailed). ${ }^{* *} p<0.01$ (twotailed). understand the antecedents of teachers' well-being. The present study aimed to examine whether the positivity ratio is associated with teachers' well-being directly and indirectly by affecting the engagement at work. Our study was an extension of the broaden-and-build theory of positive emotions (Fredrickson, $1998,2001)$ in the educational context. Our findings showed positive associations of personal resources (positivity ratio) with work engagement and well-being, supporting the JD-R model and previous studies based on it (Bakker and Demerouti, 2007; Xanthopoulou et al., 2007; Lee, 2019).

First, the hypothesized positive association of positive emotions and positivity ratio with engagement was supported. The results indicated that positive emotions (Figure 1) and the positivity ratio (Figure 2) were significantly related to higher levels of engagement (dedication, absorption, and vigor). These findings are in line with the JD-R model and studies suggesting a positive influence of positive emotions on teachers' work engagement (Buriæ and Macuka, 2018; De Stasio et al., 2019). Our results also indicated a negative effect of negative emotions on engagement (Figure 1). These findings are in line with studies showing that negative emotions are negatively related to work engagement (Buriæ and Macuka, 2018; Ferreira et al., 2019). By considering the ratio between positive and negative emotions, our results offer more light on the importance of teachers' emotions on positive occupational and personal outcomes. Besides, when investigating the positivity ratio according to participants' wellbeing, we found a mean of positivity ratio of 2.84 for the group of teachers with high levels of well-being. This finding confirms the proposed critical positivity ratio of 2.9 for adults with high levels of well-being (Fredrickson and Losada, 2005; Chen et al., 2017). Higher ratios of positive to negative emotions might also enhance learning and have positive effects on the teacher-student relationship (Cook et al., 2017; Sabey et al., 2019).

Also, as expected in the second hypothesis, we found engagement to be positively associated with teachers' well-being. These results support the JD-R model and are in line with findings showing positive associations of work engagement with well-being and job satisfaction (Shuck and Reio, 2014; Perera et al., 2018; Han et al., 2019; Yan et al., 2019).

Third, our findings provided evidence for the mediation hypotheses, revealing that teachers' engagement (dedication, absorption, and vigor) explained the effect of emotions and positivity ratio on their well-being. Our results indicate that both positive emotions and negative emotions had an indirect effect on well-being through the mediating role of engagement (Figure 1). In addition, the findings suggest that experiencing more positive than negative emotions builds teachers' engagement, which in turn broadens their well-being (Figure 2). This study confirms the beneficial effects of positive emotions on behaviors. Our findings are consistent with prior studies finding positive associations between positive emotions and psychological wellbeing (Siu et al., 2015; Lavy and Eshet, 2018). As suggested by the broaden-and-build theory, positive emotions may restore other psychological resources and protect from the detrimental effect of negative emotions (Fredrickson, 2000). The bouncing-back effect of positive emotions has been confirmed in a recent study involving teachers (Buonomo et al., 2019). 
TABLE 2 | Correlations between the study variables.

\begin{tabular}{|c|c|c|c|c|c|c|c|c|c|c|c|c|c|}
\hline Variables & 1 & 2 & 3 & 4 & 5 & 6 & 7 & 8 & 9 & 10 & 11 & 12 & 13 \\
\hline (1) Positive Affect & - & & & & & & & & & & & & \\
\hline (2) Negative Affect & 0.00 & - & & & & & & & & & & & \\
\hline (3) Positivity Ratio & $0.46^{\star *}$ & $-0.82^{\star \star}$ & - & & & & & & & & & & \\
\hline (4) Dedication & $0.36^{\star \star}$ & $-0.17^{\star *}$ & $0.32^{\star \star}$ & - & & & & & & & & & \\
\hline (5) Absorption & $0.29^{\star \star}$ & $-0.08^{\star \star}$ & $0.21^{\star *}$ & $0.70^{\star \star}$ & - & & & & & & & & \\
\hline (6) Vigor & $0.39^{\star \star}$ & $-0.19^{\star \star}$ & $0.35^{\star \star}$ & $0.81^{\star *}$ & $0.69^{\star \star}$ & - & & & & & & & \\
\hline (7) Engagement & $0.38^{\star *}$ & $-0.15^{\star \star}$ & $0.31^{\star \star}$ & $0.91^{\star \star}$ & $0.90^{\star \star}$ & $0.92^{\star \star}$ & - & & & & & & \\
\hline (8) Autonomy & $0.12^{\star \star}$ & $-0.22^{\star \star}$ & $0.26^{\star \star}$ & $0.20^{\star \star}$ & $0.11^{\star *}$ & $0.20^{* *}$ & $0.18^{\star \star}$ & - & & & & & \\
\hline (9) Personal Growth & $0.21^{\star \star}$ & $-0.26^{\star \star}$ & $0.33^{\star \star}$ & $0.31^{\star \star}$ & $0.21^{\star \star}$ & $0.31^{\star \star}$ & $0.30^{\star \star}$ & $0.46^{\star \star}$ & - & & & & \\
\hline (10) Self Acceptance & $0.20^{\star \star}$ & $-0.33^{\star \star}$ & $0.38^{\star \star}$ & $0.31^{\star *}$ & $0.20^{\star \star}$ & $0.32^{\star *}$ & $0.30^{\star \star}$ & $0.48^{\star \star}$ & $0.70^{\star \star}$ & - & & & \\
\hline (11) Positive Relations & $0.24^{\star \star}$ & $-0.26^{\star \star}$ & $0.34^{\star \star}$ & $0.31^{\star *}$ & $0.20^{\star \star}$ & $0.32^{\star \star}$ & $0.30^{\star \star}$ & $0.41^{\star \star}$ & $0.70^{\star \star}$ & $0.74^{\star \star}$ & - & & \\
\hline (12) Environmental Mastery & $0.27^{\star \star}$ & $-0.31^{\star *}$ & $0.40^{\star \star}$ & $0.34^{\star \star}$ & $0.23^{\star \star}$ & $0.38^{\star \star}$ & $0.35^{\star *}$ & $0.49^{\star \star}$ & $0.74^{\star \star}$ & $0.80^{\star \star}$ & $0.74^{\star \star}$ & - & \\
\hline (13). Purpose in life & $0.19^{\star \star}$ & $-0.27^{\star \star}$ & $0.32^{\star \star}$ & $0.32^{\star \star}$ & $0.20^{\star \star}$ & $0.32^{\star \star}$ & $0.30^{\star *}$ & $0.48^{\star \star}$ & $0.78^{\star \star}$ & $0.81^{\star \star}$ & $0.72^{\star \star}$ & $0.81^{\star \star}$ & - \\
\hline (14) Well-Being & $0.24^{\star \star}$ & $-0.33^{\star \star}$ & $0.40^{\star \star}$ & $0.35^{\star \star}$ & $0.23^{\star \star}$ & $0.37^{\star \star}$ & $0.34^{\star \star}$ & $0.63^{\star \star}$ & $0.86^{\star \star}$ & $0.90^{\star \star}$ & $0.86^{\star \star}$ & $0.90^{\star \star}$ & $0.91^{\star *}$ \\
\hline
\end{tabular}

${ }^{* *} p<0.01$ (two-tailed). $n=1335$ participants.

\section{Educational Implications}

Initial training of teachers should focus more on strategies to promote positive emotions and to regulate negative emotions in times of stress. The results of our study emphasize the importance of addressing both negative and positive emotions in prevention and intervention programs with teachers. Based on our findings, experiencing about three times more positive than negative emotions in daily life could help teachers to increase their engagement and well-being. In order to experience more positive emotions, teachers might also benefit from specific interventions that might be drawn from positive psychology, such as mindfulness meditation, loving-kindness meditation (see, for review, Garland et al., 2010), interventions focused on workfamily balance (Crain et al., 2017), and cultivation of positive teacher-student relationships (Cook et al., 2018). Moreover, teachers' positive emotions and engagement could be cultivated through poetry, martial arts, and music, as these practices have been related to higher levels of flourishing and engagement (Croom, 2012, 2014, 2015).

Our findings support the importance of addressing positive emotions in programs aimed to build teachers' engagement. Existing studies provided evidence for the effectiveness of work engagement interventions focused on personal resources (Knight et al., 2017, 2019; Van Wingerden et al., 2017). However, as organizational and national characteristics have been found to affect the effectiveness of interventions on engagement, it is important to adapt these interventions to teachers in different countries. In addition, our results emphasize the importance of interventions targeting employees' well-being based on PERMA theory (i.e., positive emotions, engagement, relationships, meaning, and accomplishment) (Seligman, 2011).

\section{Strengths and Limitations}

The present study has many strengths including considering in the same study both positive and negative emotions and the ratio between them, using a large sample size, and using an understudied sample of teachers from Eastern Europe. The limits of our study are related to teachers' self-reports and crosssectional design. Future studies should focus on longitudinal associations between teachers' emotions, engagement, and long-term well-being, as change in emotions across time is an important predictor of psychological well-being (Houben et al., 2015). Daily-diary data would help to better understand whether teachers report higher levels of engagement and well-being on days when they experienced more positive than negative emotions. Future studies exploring daily dynamics of teachers' emotions would also help us to examine the upward spiral of positive emotions; teachers' engagement might predict further increases in positive emotions, which in turn would positively affect their well-being. Future studies should also focus on other specific positive emotions, such as gratitude, compassion, self-compassion, forgiveness, hope, and amusement, and negative emotions, such as boredom and anger. Despite the limitations, our study contributes to a better understanding of the mechanisms relating teachers' emotions to work engagement and psychological wellbeing. Besides, our findings point out important targets for interventions designed to improve teachers' work engagement and well-being.

\section{DATA AVAILABILITY STATEMENT}

The datasets generated for this study are available on request to the corresponding author.

\section{ETHICS STATEMENT}

The present study was reviewed and approved by Ethical Commission of Scientific Research, University "Ştefan cel Mare" of Suceava, Romania. The participants provided their written informed consent to participate in this study. 


\section{AUTHOR CONTRIBUTIONS}

AC planned the design of the study, organized the data collection, and drafted the methods section. Both authors developed the presented idea, and approved the submitted

\section{REFERENCES}

Bakker, A. B., and Demerouti, E. (2007). The job demands-resources model: state of the art. J. Manager. Psychol. 22, 309-328. doi: 10.1108/02683940710733115

Bakker, A. B., Hetland, J., Olsen, O. K., and Espevik, R. (2019). Daily strengths use and employee well-being: the moderating role of personality. J. Occup. Organ. Psychol. 92, 144-168. doi: 10.1111/joop.12243

Basińska, B. A., and Gruszczyńska, E. (2017). Positivity and job burnout in emergency personnel: examining linear and curvilinear relationship. Polish Psychol. Bull. 48, 212-219. doi: 10.1515/ppb-2017-0024

Branand, B., and Nakamura, J. (2016). "The well-being of teachers and professors," in The Wiley Blackwell Handbook of the Psychology of Positivity and Strengths Based Approaches at Work, eds L. G. Oades, M. F. Steger, A. D. Fave, and J. Passmore (Chichester: John Wiley \& Sons, Ltd), 466-490. doi: 10.1002/ 9781118977620.ch24

Brígido, M., Borrachero, A. B., Bermejo, M. L., and Mellado, V. (2013). Prospective primary teachers' self-efficacy and emotions in science teaching. Eur. J. Teach. Educ. 36, 200-217. doi: 10.1080/02619768.2012.686993

Brown, N. J. L., Sokal, A. D., and Friedman, H. L. (2013). The complex dynamics of wishful thinking: the critical positivity ratio. Am. Psychol. 68, 801-813. doi: 10.1037/a0032850

Buonomo, I., Fiorilli, C., and Benevene, P. (2019). The impact of emotions and hedonic balance on teachers' self-efficacy: testing the bouncing back effect of positive emotions. Front. Psychol. 10:1670. doi: 10.3389/fpsyg.2019.01670

Buonomo, I., Fiorilli, C., and Benevene, P. (2020). Unravelling teacher job satisfaction: the contribution of collective efficacy and emotions towards professional role. Int. J. Environ. Res. Public Health 17:736. doi: 10.3390/ ijerph17030736

Buriæ, I., and Macuka, I. (2018). Self-efficacy, emotions and work engagement among teachers: a two wave cross-lagged analysis. J. Happin. Stud. 19, 19171933. doi: 10.1007/s10902-017-9903-9

Buriæ, I., and Moè, A. (2020). What makes teachers enthusiastic: the interplay of positive affect, self-efficacy and job satisfaction. Teach. Teach. Educ. 89:103008. doi: 10.1016/j.tate.2019.103008

Buriæ, I., Sliškoviæ, A., and Macuka, I. (2018). A mixed-method approach to the assessment of teachers' emotions: development and validation of the Teacher Emotion Questionnaire. Educ. Psychol. 38, 325-349. doi: 10.1080/01443410. 2017.1382682

Buriæ, I., Sliškoviæ, A., and Peneziæ, Z. (2019). A two-wave panel study on teachers' emotions and emotional-labour strategies. Stress Health 35, 27-38. doi: $10.1002 /$ smi.2836

Capone, V., Joshanloo, M., and Park, M. S.-A. (2019). Burnout, depression, efficacy beliefs, and work-related variables among school teachers. Int. J. Educ. Res. 95, 97-108. doi: 10.1016/j.ijer.2019.02.001

Chen, J. (2019a). Efficacious and positive teachers achieve more: examining the relationship between teacher efficacy, emotions, and their practicum performance. Asia Pac. Educ. Res. 28, 327-337. doi: 10.1007/s40299-018-0427-9

Chen, J. (2019b). Exploring the impact of teacher emotions on their approaches to teaching: a structural equation modelling approach. Br. J. Educ. Psychol. 89, 57-74. doi: 10.1111/bjep.12220

Chen, S.-M., Gao, L., Zhang, Y., and Sun, P.-Z. (2017). Set points of positivity ratio for different levels of well-being: a latent profile analysis. Asian J. Soc. Psychol. 20, 211-220. doi: 10.1111/ajsp. 12185

Cook, C. R., Coco, S., Zhang, Y., Fiat, A. E., Duong, M. T., Renshaw, T. L., et al. (2018). Cultivating positive teacher-student relationships: preliminary evaluation of the establish-maintain-restore (EMR) method. Sch. Psychol. Rev. 47, 226-243. doi: 10.17105/SPR-2017-0025.V47-3

Cook, C. R., Grady, E. A., Long, A. C., Renshaw, T., Codding, R. S., Fiat, A., et al. (2017). Evaluating the impact of increasing general education teachers' ratio of positive-to-negative interactions on students' classroom version. PR drafted the introduction, results, and discussion, contributed to an adequate statistical implementation of the presented idea, and computed the statistical analyses. PR contributed to the manuscript equally as $\mathrm{AC}$ and shares the first authorship.

behavior. J. Posit. Behav. Intervent. 19, 67-77. doi: 10.1177/109830071667 9137

Crain, T. L., Schonert-Reichl, K. A., and Roeser, R. W. (2017). Cultivating teacher mindfulness: effects of a randomized controlled trial on work, home, and sleep outcomes. J. Occup. Health Psychol. 22, 138-152. doi: 10.1037/ocp000 0043

Croom, A. M. (2012). Music, neuroscience, and the psychology of well-being: a précis. Front. Psychol. 2:393. doi: 10.3389/fpsyg.2011.00393

Croom, A. M. (2014). Embodying martial arts for mental health: cultivating psychological wellbeing with martial arts practice. Arch. Budo Sci. Martial Arts Extreme Sports 10, 59-70.

Croom, A. M. (2015). The practice of poetry and the psychology of well-being. J. Poet. Ther. 28, 21-41. doi: 10.1080/08893675.2015.980133

De Stasio, S., Fiorilli, C., Benevene, P., Boldrini, F., Ragni, B., Pepe, A., et al. (2019). Subjective happiness and compassion are enough to increase teachers' work engagement? Front. Psychol. 10:2268. doi: 10.3389/fpsyg.2019.02268

Desouky, D., and Allam, H. (2017). Occupational stress, anxiety and depression among Egyptian teachers. J. Epidemiol. Glob. Health 7, 191-198. doi: 10.1016/j. jegh.2017.06.002

Dicke, T., Stebner, F., Linninger, C., Kunter, M., and Leutner, D. (2018). A longitudinal study of teachers' occupational well-being: applying the job demands-resources model. J. Occup. Health Psychol. 23, 262-277. doi: 10.1037/ ocp0000070

Diener, E., Thapa, S., and Tay, L. (2020). Positive emotions at work. Annu. Rev. Organ. Psychol. Organ. Behav. 7, 451-477. doi: 10.1146/annurev-orgpsych012119-044908

Ferreira, A. I., da Costa Ferreira, P., Cooper, C. L., and Oliveira, D. (2019). How daily negative affect and emotional exhaustion correlates with work engagement and presenteeism-constrained productivity. Int. J. Stress Manag. 26, 261-271. doi: $10.1037 /$ str0000114

Fredrickson, B. L. (1998). What good are positive emotions? Rev. Gen. Psychol. 2, 300-319. doi: 10.1037/1089-2680.2.3.300

Fredrickson, B. L. (2000). Why positive emotions matter in organizations: lessons from the broaden-and-build model. Psychol. Manag. J. 4, 131-142. doi: 10.1037/ h0095887

Fredrickson, B. L. (2001). The role of positive emotions in positive psychology: the broaden-and-build theory of positive emotions. Am. Psychol. 56, 218-226. doi: 10.1037/0003-066X.56.3.218

Fredrickson, B. L., and Joiner, T. (2002). Positive emotions trigger upward spirals toward emotional well-being. Psychol. Sci. 13, 172-175. doi: 10.1111/1467-9280. 00431

Fredrickson, B. L., and Joiner, T. (2018). Reflections on positive emotions and upward spirals. Perspect. Psychol. Sci. 13, 194-199. doi: 10.1177/ 1745691617692106

Fredrickson, B. L., and Losada, M. F. (2005). Positive affect and the complex dynamics of human flourishing. Am. Psychol. 60, 678-686. doi: 10.1037/0003066X.60.7.678

Frenzel, A. C. (2014). "Teacher emotions," in International Handbook of Emotions in Education, eds R. Pekrun and L. Linnenbrink-Garcia (New York, NY: Routledge, Taylor \& Francis Group).

García-Buades, M. E., Peiró, J. M., Montañez-Juan, M. I., Kozusznik, M. W., and Ortiz-Bonnín, S. (2019). Happy-productive teams and work units: a systematic review of the 'happy-productive worker thesis.'. Int. J. Environ. Res. Public Health 17:69. doi: 10.3390/ijerph17010069

Garland, E. L., Fredrickson, B., Kring, A. M., Johnson, D. P., Meyer, P. S., and Penn, D. L. (2010). Upward spirals of positive emotions counter downward spirals of negativity: insights from the broaden-and-build theory and affective neuroscience on the treatment of emotion dysfunctions and deficits in psychopathology. Clin. Psychol. Rev. 30, 849-864. doi: 10.1016/j.cpr.2010.03.002 
Gloria, C. T., Faulk, K. E., and Steinhardt, M. A. (2013). Positive affectivity predicts successful and unsuccessful adaptation to stress. Motiv. Emot. 37, 185-193. doi: 10.1007/s11031-012-9291-8

Gloria, C. T., and Steinhardt, M. A. (2016). Relationships among positive emotions, coping, resilience and mental health: positive emotions, resilience and health. Stress Health 32, 145-156. doi: 10.1002/smi.2589

Han, J., Yin, H., Wang, J., and Zhang, J. (2019). Job demands and resources as antecedents of university teachers' exhaustion, engagement and job satisfaction. Educ. Psychol. 40, 318-335. doi: 10.1080/01443410.2019.167 4249

Houben, M., Van Den Noortgate, W., and Kuppens, P. (2015). The relation between short-term emotion dynamics and psychological well-being: a meta-analysis. Psychol. Bull. 141, 901-930. doi: 10.1037/a0038822

Keller, M. M., Chang, M.-L., Becker, E. S., Goetz, T., and Frenzel, A. C. (2014). Teachers emotional experiences and exhaustion as predictors of emotional labor in the classroom: an experience sampling study. Front. Psychol. 5:1442. doi: 10.3389/fpsyg.2014.01442

Khajavy, G. H., Ghonsooly, B., and Hosseini Fatemi, A. (2017). Testing a burnout model based on affective-motivational factors among EFL teachers. Curr. Psychol. 36, 339-349. doi: 10.1007/s12144-016-9423-5

Knight, C., Patterson, M., and Dawson, J. (2017). Building work engagement: a systematic review and meta-analysis investigating the effectiveness of work engagement interventions: effectiveness of Work Engagement Interventions. J. Organ. Behav. 38, 792-812. doi: 10.1002/job.2167

Knight, C., Patterson, M., and Dawson, J. (2019). Work engagement interventions can be effective: a systematic review. Eur. J. Work Organ. Psychol. 28, 348-372. doi: 10.1080/1359432X.2019.1588887

Lavy, S., and Eshet, R. (2018). Spiral effects of teachers' emotions and emotion regulation strategies: evidence from a daily diary study. Teach. Teach. Educ. 73, 151-161. doi: 10.1016/j.tate.2018.04.001

Lee, M., and van Vlack, S. (2018). Teachers' emotional labour, discrete emotions, and classroom management self-efficacy. Educ. Psychol. 38, 669-686. doi: 10. 1080/01443410.2017.1399199

Lee, Y. (2019). JD-R model on psychological well-being and the moderating effect of job discrimination in the model: findings from the MIDUS. Eur. J. Train. Dev. 43, 232-249. doi: 10.1108/EJTD-07-2018-0059

Lesener, T., Gusy, B., and Wolter, C. (2019). The job demands-resources model: a meta-analytic review of longitudinal studies. Work Stress 33, 76-103. doi: 10.1080/02678373.2018.1529065

Lyubomirsky, S., King, L., and Diener, E. (2005). The benefits of frequent positive affect: does happiness lead to success? Psychol. Bull. 131, 803-855. doi: 10.1037/ 0033-2909.131.6.803

Malinowski, P., and Lim, H. J. (2015). Mindfulness at work: positive affect, hope, and optimism mediate the relationship between dispositional mindfulness, work engagement, and well-being. Mindfulness 6, 1250-1262. doi: 10.1007/ s12671-015-0388-5

Mencl, J., Wefald, A. J., and van Ittersum, K. W. (2016). Transformational leader attributes: interpersonal skills, engagement, and well-being. Leadersh. Organ. Dev. J. 37, 635-657. doi: 10.1108/LODJ-09-2014-0178

Moreira-Fontán, E., García-Señorán, M., Conde-Rodríguez, Á, and González, A. (2019). Teachers' ICT-related self-efficacy, job resources, and positive emotions: their structural relations with autonomous motivation and work engagement. Comput. Educ. 134, 63-77. doi: 10.1016/j.compedu.2019. 02.007

Moroń, M. (2018). Perceived emotional intelligence and life satisfaction: the mediating role of the positivity ratio. Curr. Issues Pers. Psychol. 6, 212-223. doi: 10.5114/cipp.2018.75650

Muthén, L. K., and Muthén, B. O. (1998). Mplus User's Guide, Seventh Edn. Los Angeles, CA: Muthén \& Muthén.

Orkibi, H., and Ronen, T. (2017). Basic psychological needs satisfaction mediates the association between self-control skills and subjective well-being. Front. Psychol. 8:936. doi: 10.3389/fpsyg.2017.00936

Parke, M. R., Seo, M.-G., and Sherf, E. N. (2015). Regulating and facilitating: the role of emotional intelligence in maintaining and using positive affect for creativity. J. Appl. Psychol. 100, 917-934. doi: 10.1037/a0038452

Perera, H. N., Granziera, H., and McIlveen, P. (2018). Profiles of teacher personality and relations with teacher self-efficacy, work engagement, and job satisfaction. Pers. Individ. Diff. 120, 171-178. doi: 10.1016/j.paid.2017. 08.034

Robledo, E., Zappalà, S., and Topa, G. (2019). Job crafting as a mediator between work engagement and wellbeing outcomes: a time-lagged study. Int. J. Environ. Res. Public Health 16:1376. doi: 10.3390/ijerph16081376

Ryff, C. D. (1989). Happiness is everything, or is it? Explorations on the meaning of psychological well-being. J. Pers. Soc. Psychol. 57, 1069-1081. doi: 10.1037/ 0022-3514.57.6.1069

Sabey, C. V., Charlton, C., and Charlton, S. R. (2019). The "Magic" positive-to-negative interaction ratio: benefits, applications, cautions, and recommendations. J. Emot. Behav. Disord. 27, 154-164. doi: 10.1177/1063 426618763106

Schaufeli, W. B., Salanova, M., González-romá, V., and Bakker, A. B. (2002). The measurement of engagement and burnout: a two sample confirmatory factor analytic approach. J. Happin. Stud. 3, 71-92. doi: 10.1023/A:1015630930326

Schermelleh-Engel, K., Moosbrugger, H., and Müller, H. (2003). Evaluating the fit of structural equation models: tests of significance and descriptive goodness-offit measures. Methods of Psychological Research Online, 8, 23-74.

Seligman, M. E. P. (2011). Flourish: A Visionary New Understanding of Happiness and Well-Being. New York, NY: Free Press.

Seppälä, P., Mauno, S., Feldt, T., Hakanen, J., Kinnunen, U., Tolvanen, A., et al. (2009). The construct validity of the utrecht work engagement scale: multisample and longitudinal evidence. J. Happin. Stud. 10, 459-481. doi: 10. 1007/s10902-008-9100-y

Shrira, A., Bodner, E., and Palgi, Y. (2016). Positivity ratio of flourishing individuals: examining the moderation effects of methodological variations and chronological age. J. Posit. Psychol. 11, 109-123. doi: 10.1080/17439760.2015. 1037857

Shuck, B., and Reio, T. G. (2014). Employee engagement and well-being: a moderation model and implications for practice. J. Leadersh. Organ. Stud. 21, 43-58. doi: 10.1177/1548051813494240

Siu, O. L., Cheung, F., and Lui, S. (2015). Linking positive emotions to work wellbeing and turnover intention among hong kong police officers: the role of psychological capital. J. Happin. Stud. 16, 367-380. doi: 10.1007/s10902-0149513-8

Sonnentag, S., Mojza, E. J., Binnewies, C., and Scholl, A. (2008). Being engaged at work and detached at home: a week-level study on work engagement, psychological detachment, and affect. Work Stress 22, 257-276. doi: 10.1080/ 02678370802379440

Taxer, J. L., and Frenzel, A. C. (2015). Facets of teachers' emotional lives: a quantitative investigation of teachers' genuine, faked, and hidden emotions. Teach. Teach. Educ. 49, 78-88. doi: 10.1016/j.tate.2015.03.003

Tesi, A., Aiello, A., and Giannetti, E. (2019). The work-related well-being of social workers: framing job demands, psychological well-being, and work engagement. J. Soc. Work 19, 121-141. doi: 10.1177/146801731875 7397

Van Wingerden, J., Derks, D., and Bakker, A. B. (2017). The impact of personal resources and job crafting interventions on work engagement and performance. Hum. Resour. Manag. 56, 51-67. doi: 10.1002/hrm.21758

Wang, H., Hall, N. C., and Taxer, J. L. (2019). Antecedents and consequences of teachers' emotional labor: a systematic review and meta-analytic investigation. Educ. Psychol. Rev. 31, 663-698. doi: 10.1007/s10648-019-09475-3

Watson, D., Clark, L. A., and Tellegen, A. (1988). Development and validation of brief measures of positive and negative affect: the PANAS scales. J. Pers. Soc. Psychol. 54, 1063-1070. doi: 10.1037//0022-3514.54.6.1063

Xanthopoulou, D., Bakker, A. B., Demerouti, E., and Schaufeli, W. B. (2007). The role of personal resources in the job demands-resources model. Int. J. Stress Manag. 14, 121-141. doi: 10.1037/1072-5245.14.2.121

Yan, X., Su, J., Wen, Z., and Luo, Z. (2019). The role of work engagement on the relationship between personality and job satisfaction in chinese nurses. Curr. Psychol. 38, 873-878. doi: 10.1007/s12144-017-9667-8

Yin, H. (2015). The effect of teachers' emotional labour on teaching satisfaction: moderation of emotional intelligence. Teach. Teach. 21, 789-810. doi: 10.1080/ 13540602.2014.995482

Yin, H., Huang, S., and Chen, G. (2019). The relationships between teachers' emotional labor and their burnout and satisfaction: a meta-analytic review. Educ. Res. Rev. 28:100283. doi: 10.1016/j.edurev.2019.100283 
Yin, H., Huang, S., and Lv, L. (2018). A multilevel analysis of job characteristics, emotion regulation, and teacher well-being: a job demands-resources model. Front. Psychol. 9:2395. doi: 10.3389/fpsyg.2018. 02395

Yin, H., Huang, S., and Wang, W. (2016). Work environment characteristics and teacher well-being: the mediation of emotion regulation strategies. Int. J. Environ. Res. Public Health 13:907. doi: 10.3390/ijerph13090907

Zito, M., Cortese, C. G., and Colombo, L. (2019). The role of resources and flow at work in well-being. SAGE Open 9:215824401984973. doi: 10.1177/ 2158244019849732
Conflict of Interest: The authors declare that the research was conducted in the absence of any commercial or financial relationships that could be construed as a potential conflict of interest.

Copyright (c) 2020 Rusu and Colomeischi. This is an open-access article distributed under the terms of the Creative Commons Attribution License (CC BY). The use, distribution or reproduction in other forums is permitted, provided the original author(s) and the copyright owner(s) are credited and that the original publication in this journal is cited, in accordance with accepted academic practice. No use, distribution or reproduction is permitted which does not comply with these terms. 